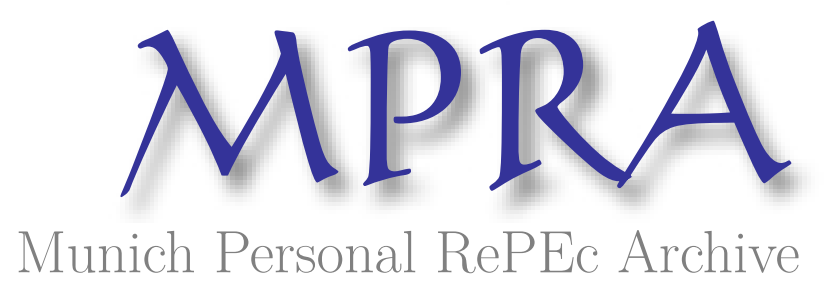

\title{
The cost of capital in markets with opaque intermediaries and the risk-structure of interest rates
}

Mierzejewski, Fernando

K.U.Leuven

1 May 2009

Online at https://mpra.ub.uni-muenchen.de/14942/

MPRA Paper No. 14942, posted 05 May 2009 23:57 UTC 


\title{
The Cost of Capital in Markets with Opaque Intermediaries and the Risk-Structure of Interest Rates
}

\author{
May 2009 \\ Fernando Mierzejewski ${ }^{\dagger}$ \\ ${ }^{\dagger}$ Faculty of Business and Economics, Katholieke Universiteit Leuven, Naamsestraat 69, \\ 3000 Leuven, Belgium. \\ Email: femierze@lycos.com \\ \$Presented to the 8th Journees Louis-Andre Gerard-Varet - Conference in Public Eco- \\ nomics. Organised by the Institut D'Economie Publique — IDEP. June, 15-16th 2009. \\ Marseille, France.
}

\begin{abstract}
The demand for cash balances of financial intermediaries that establish contractual liabilities with credit-sensitive customers is characterised. As stated by Merton, the success of the business activities of such firms crucially depends on their credit quality. They are thus obliged to rely on deposit insurance and capital cushions in order to assure that their promised payments are free of default. Unlike the Merton's approach, the optimal guaranteeing contract is formulated in actuarial terms in this paper, because in this way the model can be extended to consider the situation of firms that can only hedge up to a limited extent. Within this framework, the equilibrium in the market determines the rate at which a unit of capital is exchange by a unit of risk, or, in other words, it determines the market price of risk. Episodes of liquidity crises are meaningful in this theoretical setting.
\end{abstract}

Key words: The cost of capital; Liquidity preference; Quantity theory; Financial instability; Liquidity crises.

JEL-Classification: E41, E44, G14, G15.

\section{Introduction}

Investors holding financial securities with random outcomes are exposed to unknown balances equal to the differences between the market values of outstanding assets and liabilities. When positive, such surpluses can be lent at the overnight interest rate in order to avoid keeping idle money. Short-term debt can be attracted, on the other hand, when a net loss is suffered. Modigliani and Miller (1958) have noticed that, since in perfect capital markets such operations can be performed without restrictions, rational decisionmakers - who are assumed to maximise value — should demand no cash holdings, for it is costly and provides no benefit. However, frictions in capital markets can prevent this mechanism to fully operate in practice. As a matter of fact, premiums are normally charged on market prices depending on credit-ratings and the size of loans, evidencing 
that the cost of debt restructuring can be incremented when the magnitude of losses increases up to certain levels. Those firms that cannot afford such extra costs are forced to default. Under such circumstances, the financial position and so the performance of companies are affected by their capital structure.

Merton (1997) proposes a model to determine the price of insuring liabilities established by opaque financial intermediaries with credit-sensitive customers - where creditsensitivity characterises the attitude of individuals expecting that promised payments are delivered with certainty, while opacity refers to the fact that the business activities of financial institutions are normally unknown to outsiders. Customers are additionally assumed to show aversion-to-risk and to lack the expertise to diversify and to hedge efficiently. Thus the role of financial intermediaries is that of providing insured liability contracts to customers that cannot continuously modify their portfolios. The efficiency of such services crucially depends on the perceptions of customers about the credit quality of the intermediary.

A fundamental assumption in the model of Merton is that financial intermediaries can hedge continuously and efficiently and that they can accordingly sell this service to their customers. But what is the situation in markets where even the most solvent institutions can only hedge up to a limited extent? After all, every financial company stops relying on trading at some limit and prefer to call instead for reinsurance and risk capital cushions. An actuarial approach is proposed in this paper to describe this situation, according to which (in a similar way to that adopted by Merton, 1974 and 1977), the optimal surpluses of shareholders and guarantors are respectively determined at the levels where the value of the firm is maximised and where the cost of bankruptcy is minimised. Then, as demonstrated in Section 2, the optimal levels of reserves are determined by the quantile functions of the series of capital returns of the intermediaries' portfolios.

The total cash balance demanded by the market is defined in Section 3 as the sum of the surpluses demanded by customers and financial intermediaries. The cost of capital is then determined in order to satisfy the necessary condition that the total demand for capital is equal to the total balance supplied by creditors. As demonstrated in Section 4, such equilibrium actually determines a set of combinations of the supply of capital, the total balance spent on the transaction of securities, the rate of interest $r$, and the pair of the expected return and the volatility of the market portfolio.

On these grounds, the cost of capital in financial markets is defined by the probability that the market capital loss surpasses the ratio of the supply of cash balances to the volume of funds spent in the transactions of securities, or, in other words, it is equal to the probability that the cash-guarantee maintained at the aggregated level is insufficient to cover the total realised loss. Alternatively, it can be interpreted as the return to be paid for holding a given uncertain claim instead of investing on a non-risky zerocoupon bond with a predetermined maturity. Such a rate corresponds to the return to be obtained when investing one monetary unit on the underlying risk and can accordingly be regarded as the Internal Rate of Return on Risk (IRRR). Therefore, every pair of equity and transactions volume determines a Risk-Structure of Interest Rates over the plane of expected returns and volatilities, providing the price to be asked for exchanging a given risk for equity. Such structure of interest rates is studied in Section 5. 
The analysis of the elasticity of the demand for cash balances with respect to the interest rate and the shape of the risk-structure of interest rates in Sections 4 and 5 leads to a precise description of financial markets in terms of the capital flows and the risk-parameters of the market portfolio. More specifically, the derived expressions for the preference for liquidity and the internal rate of return on risk, which are dependent on observable variables, can be regarded as measures of the liquidity conditions in the market. On the grounds of a partial equilibrium approach, different states can be compared, thus allowing to distinguish the more stable and the more vulnerable to violent adjustments. The empirical analysis carried on in Sections 6, 7 and 8 illustrates the kind of representation that can be obtained from the model. In particular, the liquidity crises occurred in October 1987 and April 2000 (the Black Monday and the dot-com bubble) can be satisfactorily interpreted in terms of the paths followed by the empirical expected returns and volatilities of the series of capital returns of the corresponding indexes. Section 9 concludes the paper.

\section{The Optimal Demand for Cash Balances}

According to Merton (1997), the capital structure affects the value of firms that establish contractual liabilities with customers who are sensible to the default-risk implicit in their deposits. Such customers are characterised by the unwillingness to share the risk taken by intermediaries - even if they were offered a fair premium reduction - a situation that is aggravated due to the fact that the business activities of financial companies are usually unknown to outsiders, i.e. these institutions are opaque to outsiders. Additionally, customers are supposed to lack the expertise required to diversify or to hedge by themselves, and they are also assumed to face higher transaction costs. By contrast, the investors in the stocks and bonds issued by financial companies agree to afford the cost of bankruptcy, provided they are compensated by the appropriate expected return. In this context, the role of financial intermediation is to attract funds from risk-neutral investors and from averse-to-risk customers to hold financial assets. The success of this kind of firms critically depends on their ability to assure to their customers that the promised payments will be made with certainty.

Three different strategies are available to provide protection against default-risk: hedging, insuring and risk-capital cushions. In the model of Merton (1997), intermediaries show preference for hedging. Two different option-based contracts are then established, one involving the firm and stockholders and delivering the excess of the value of net assets (equal to assets minus liabilities) over the level of cash holdings, and another involving the firm and some external guarantor, who guarantees the cash flows promised to customers. The surplus $S$ of the intermediary is then represented by the market value of net assets, which is supposed to follow a Brownian motion. Then both the value of the firm and the value of the guarantee are contingent on the value of net assets. The optimal contracts established with shareholders and guarantors can thus be respectively established in order to maximise the value of the firm and to minimise the cost of bankruptcy (see also Merton, 1974, 1977).

However (as already stated by Merton, 1997), the distinction between intermediaries, 
guarantors, customers and investors can be difficult in actual financial markets. As a matter of fact, some financial institutions acting as guarantors to some firms or individual investors, can be customers of or investors in other companies. Eventually, every financial institution will stop relying on hedging and will seek for reinsuring and risk capital to assure the solvency of its business activities. The capital structure of this kind of firms will be next characterise. As in the model of Merton, two contracts will be defined, one involving the maximisation of the value of the firm, and the other involving the minimisation of the cost of insolvency. But since these will be now supposed to be insuring contracts, an actuarial setting will be required.

In order to establish these contracts in formal terms, let us assume that every intermediary holds a net-portfolio combining capital and some Gaussian exposure $X$, characterised by a pair of expected return and volatility $(\mu, \sigma)$ and corresponded to the series of (random) capital Profit and Losses (PESL) of the value $V$ of the underlying fund. Since each monetary unit invested on risk produces the percentage return $X$, the total $P \& L$ accrued by the underlying fund must be equal to:

$$
L \cdot X=L \cdot \Delta V \quad \text { with } \quad X_{t}=\frac{V_{t}-V_{t-1}}{V_{t-1}} \forall t
$$

where the variable $L$ denotes the amount of funds spent on transactions. The random variable $X$ can be certainly related to the surplus $S$ defined by Merton, but recall that $X$ has been expressed in percentage terms - in such a way that the absolute return is also dependent on the transactions volume.

Let us additionally express the magnitude of the guarantee, in the following denoted by $K$, as a proportion $k$ of the transactions volume, such that $K=L \cdot k$. The agreements established by the financial intermediary are then defined in the following way. On the one hand, stockholders supply the balance $K=L \cdot k$ with the promise of receiving the return in excess $(X-k)$ if the firm is solvent, i.e. if $X>k$. On the other hand, the firm establishes a contract with some insurance company that promises to pay the excess of loss $(X+k)$ when bankruptcy is declared, i.e. when $X<-k$. Hence the payments delivered to stockholders and received from guarantors at the end of the investment period are respectively equal to $L \cdot(X-k)$ and $L \cdot(X+k)$.

As long as the amount of capital $K$ could be alternatively invested in some fixed-term deposit to obtain the return $r \cdot K$, the total benefit $Y^{S}$ delivered to stockholders and the total cost $Y^{G}$ endured by the guarantor and the firm at the end of the investment period, per unit spent on securities, are respectively given by:

$$
\begin{gathered}
Y^{S}=(X-k)+r \cdot k \quad \text { when } X>k \\
Y^{G}=-(X+k)+r \cdot k \quad \text { when } X<-k
\end{gathered}
$$

which can be equivalently expressed as:

$$
\begin{aligned}
& Y^{S}=(X-k)_{+}+r \cdot k=\max (0, X-k)+r \cdot k \\
& Y^{G}=(X+k)_{-}+r \cdot k=-\min (0, X+k)+r \cdot k
\end{aligned}
$$


Whenever $-k \leq X \leq k$, no capital gains are obtained and additional debt is required to pay the guarantee back, though the size of the losses is bounded by the level of reserves. Stockholders are expected to sell their shares or to call for restructuring in this case.

On these grounds, two different kind of firms can be distinguished. There are, in the first place, firms that seek to maintain their relationship with stockholders in the best terms and accordingly seek to maximise the return $Y^{S}$. In the second place, there are firms more concerned about their relationship with guarantors and customers that accordingly prefer to minimise the return $Y^{G}$. While those firms belonging to the first group can be regarded as speculative firms, as long as their focus on profits may lead them to implement more aggressive investment strategies, those in the second group can be regarded as precautionary firms, as long as their objective is to reduce their exposure to risk to a minimum.

Since the capital return $X$ is represented by a random variable, both $Y^{S}$ and $Y^{G}$ are also represented by random variables, which means that the optimal surpluses should be determined based on the expected values of the residual exposures $E\left[(X-k)_{+}\right]$and $E\left[(X+k)_{-}\right]$. Recall that any random variable can be equivalently represented by its cumulative probability function $F_{X}$ or its tail probability function $T_{X}$, functions that are related to each other through the fundamental identity:

$$
T_{X}(k)=P[X>k]=1-P[X \leq k]=1-F_{X}(k)
$$

Besides, in a Gaussian setting, both functions can be expressed in terms of the cumulative probability $\Phi$ of the standard Gaussian, whose mean return and volatility are respectively equal to zero and one:

$$
T_{X}(k)=1-F_{X}(k)=1-\Phi\left(\frac{k-\mu}{\sigma}\right)
$$

In fact, the Gaussian cumulative and tail probability function are explicitly defined as:

$$
\begin{aligned}
& F_{X}(k)=P[X \leq k]=\int_{-\infty}^{k} d F_{X}(x)=\frac{1}{\sigma \sqrt{2 \pi}} \cdot \int_{-\infty}^{k} \exp \left[\frac{-(x-\mu)^{2}}{2 \sigma^{2}}\right] d x \\
& T_{X}(k)=P[X>k]=\int_{k}^{+\infty} d F_{X}(x)=\frac{1}{\sigma \sqrt{2 \pi}} \cdot \int_{k}^{+\infty} \exp \left[\frac{-(x-\mu)^{2}}{2 \sigma^{2}}\right] d x
\end{aligned}
$$

Applying the mathematical definition of the expectation operator we obtain that:

$$
E\left[(X-k)_{+}\right]=\int_{+k}^{+\infty}(x-k) \cdot d F_{X}(x)=\frac{1}{\sigma \sqrt{2 \pi}} \cdot \int_{+k}^{+\infty}(x-k) \cdot \exp \left[\frac{-(x-\mu)^{2}}{2 \sigma^{2}}\right] d x
$$

and also:

$$
E\left[(X+k)_{-}\right]=-\int_{-\infty}^{-k}(x+k) \cdot d F_{X}(x)=-\frac{1}{\sigma \sqrt{2 \pi}} \cdot \int_{-\infty}^{-k}(x+k) \cdot \exp \left[\frac{-(x-\mu)^{2}}{2 \sigma^{2}}\right] d x
$$


Let us now investigate how the optimal balance of precautionary firms is determined. These firms minimise the expected loss endured by the guarantor in case of default plus the opportunity cost of capital, and thereby solve the following optimisation problem:

$$
\min _{k} E\left[(X+k)_{-}\right]+r \cdot k
$$

Applying the Leibniz integral rule for the differentiation of a definite integral whose limits are functions of the differential variable, ${ }^{1}$ we obtain from Equation 4 that:

$$
\frac{\partial}{\partial k} E\left[(X+k)_{-}\right]=-\int_{-\infty}^{-k} 1 \cdot d F_{X}(x)=-T_{-X}(k)
$$

Then the first-order condition of the problem of Equation 5 leads to:

$$
\frac{\partial}{\partial k} E\left[\left(X+k^{*}\right)_{-}\right]+r=-T_{-X}\left(k^{*}\right)+r=0
$$

The second-order condition additionally implies that the functional $E\left[(X+k)_{-}\right]$is in fact a convex function of the level of capital and hence, that the optimal proportional of capital $k^{*}$ actually leads to a minimum value of the optimisation criterion:

$$
\frac{\partial^{2}}{\partial k^{2}} E\left[(X+k)_{-}\right]=-\frac{d T_{-X}(k)}{d k}>0 \forall k
$$

The optimal cash balance of precautionary firms is then equal to:

$$
k_{\mu, \sigma}(r)=\sigma \cdot \Phi^{-1}(1-r)-\mu
$$

Consequently, the optimal capital demand of precautionary firms always follows a nonincreasing and continuous path, for both the cumulative function $\Phi$ and its inverse are non-decreasing and continuous functions of their arguments. Discrepancies relative to preferred cash-balances are thus explained on the basis of the underlying risks and the opportunity cost of capital. Besides, the minimum and maximum levels of surplus are respectively demanded when $r \geq 1$ and $r \leq 0$.

Speculative firms, on the other hand, maximise the expected excess return and accordingly solve the following optimisation problem:

$$
\max _{k} E\left[(X-k)_{+}\right]+r \cdot k
$$

\footnotetext{
${ }^{1}$ According to this rule:$$
\frac{\partial}{\partial z} \int_{u(z)}^{v(z)} f(x, z) d x=\int_{u(z)}^{v(z)} \frac{\partial f(x, z)}{\partial z} d x+f(v(z), z) \cdot \frac{\partial v(z)}{\partial z}-f(u(z), z) \cdot \frac{\partial u(z)}{\partial z}
$$ 
But again the second-order condition leads to the existence of an optimal capital proportion that minimises (and does not maximise) the optimisation criterion:

$$
\frac{\partial^{2}}{\partial k^{2}} E\left[(X-k)_{+}\right]=-\frac{d T_{X}(k)}{d k}>0 \forall k
$$

Hence every unit invested on risk capital represents an undesired burden for speculative firms, which produces an average loss that can be explicitly determined:

$$
E\left[X_{+}\right]>E\left[(X-k)_{+}\right]+r \cdot k \Longrightarrow \frac{E\left[X_{+}\right]-E\left[(X-k)_{+}\right]}{k}>r
$$

As long as the average cost they incurred when supplying capital is higher than the alternative interest $r$ they have to pay for attracting funds in the market, speculative firms maintain no reserves at all - as predicted by the Modigliani-Miller proposition. As a conclusion, financial intermediaries only demand capital due to precautionary motives, and they do it according to the optimal level specified in Equation 6.

From the actuarial point of view, the term $E\left[(X+k)_{-}\right]$represents the excess of loss suffered by the issuer of some insuring policy covering the loss of the mutual fund $X$, where the retention or deductible is equal to $k$. Such a contract is known as a layer in the actuarial literature. The deductible is introduced in these contracts in order to assure that the holder of the policy will take every reasonable care to reduce the probability and the magnitude of losses. It then explicitly accounts for the moral-hazard inherent in the agreement - because insurers cannot directly observe the behaviour of policyholders. On these grounds, the optimal cash balance, as determined by Equation 6, can be corresponded to the optimal retention or optimal deductible of the related deposit insurance contract. In the next section, the aggregated money demand of the market will be characterised by the sum of the optimal balances determined at the microscopic level.

\section{The Aggregate Demand for Cash Balances}

The amount of reserves demanded by the market will be characterised in the following by adding the cash balances maintained at different levels of aggregation, going from investors and small firms, to big companies, conglomerates, industries and economic sectors. Assuming that the individual exposures are distributed as Gaussians with means $\mu_{1}, \ldots, \mu_{n}$ and volatilities $\sigma_{1}, \ldots, \sigma_{n}$, we obtain from Equation 6 that the optimal balances demanded by precautionary firms are given by:

$$
k_{i}(r)=\sigma_{i} \cdot \Phi^{-1}(1-r)-\mu_{i} \quad \forall i=1, \ldots, n
$$

Summing up these balances we obtain that the total level of reserves $K^{M}$ demanded by the market is equal to:

$$
K^{M}=\sum_{i=1}^{n} L_{i} \cdot k_{i}(r)=\Phi^{-1}(1-r) \cdot \sum_{i=1}^{n} L_{i} \sigma_{i}-\sum_{i=1}^{n} L_{i} \mu_{i}
$$


where $L_{1}, \ldots, L_{n}$ denote the amounts of funds spent in each of the risks $X_{1}, \ldots, X_{n}$. Define $L=L_{1}+\cdots+L_{n}$ as the total funds spent in the market, in such a way that:

$$
K^{M}=L \cdot\left(\Phi^{-1}(1-r) \cdot \sum_{i=1}^{n} \frac{L_{i}}{L} \sigma_{i}-\sum_{i=1}^{n} \frac{L_{i}}{L} \mu_{i}\right)
$$

Hence the contributions of the individual exposures to the aggregate demand for cash balances are given by the coefficients $\omega_{1}, \ldots, \omega_{n}$, defined as:

$$
\omega_{i}=\frac{L_{i}}{L_{1}+\cdots+L_{n}} \Leftrightarrow L_{i}=\omega_{i} \cdot L \quad \forall i=1, \ldots, n
$$

Consequently, the liquidity-preference of the market $k^{M}=K^{M} / L$ must be defined as:

$$
k^{M}(r)=k_{\mu, \sigma}(r)=\sigma \cdot \Phi^{-1}(1-r)-\mu
$$

with:

$$
\mu=\sum_{i=1}^{n} \omega_{i} \cdot \mu_{i} \quad \text { and } \quad \sigma=\sum_{i=1}^{n} \omega_{i} \cdot \sigma_{i}
$$

Note that assuming that the optimal surpluses are determined by Equation 8 does not necessarily imply that investors solve an optimisation problem before deciding their cash balances. However, as long as for every fund an optimal balance exists, there are incentives to accordingly adjust the capital structure, for big departures from this level can produce important losses and eventually lead to bankruptcy. Simple calibration and backtesting can be used to attain this objective. Thus, whatever the mechanism implemented to determine their levels of capital - going from a rule of thumb to complicated mathematical modeling - firms will be assumed to approach as much as possible to the optimal levels corresponded to their portfolios. On these grounds, a weak version of the hypothesis of rational behaviour is proposed, according to which the successive aggregate states will be characterised by adding the risk-based contributions of investors who combine equity and financial assets trying to build optimal portfolios.

The model of liquidity-preference presented so far can be regarded as an alternative to the utility maximisation approach, according to which the demand for liquidity is represented by the surplus demanded by some representative rational decision-maker who maximises her or his expected utility (see e.g. Choi and Oh, 2003, and Holmstrom and Tirole, 2000). This approach is first suggested by Tobin (1958) when characterising liquidity-preference as behaviour towards risk.

The following problems arise, however, when implementing the utility maximisation approach. Thus, in the first place, the expressions derived for the money demand from the first-order condition are not easy to work with and they cannot then be clearly interpreted in terms of measurable economic variables. Secondly, recall that a parametrical 
expression has to be determined for the utility function, as well as for the parameter representing the aversion-to-risk of the decision-maker. Since this coefficient is not observable, the model eventually depends on exogenous variables that have to be determined on a subjective basis. As a consequence, every event of significance (involving adjustments beyond expected) has to be explained on the basis of exogenous events, like the sudden release of relevant information or the sudden change in the mood of investors - from risk-aversion to risk-loving or in the opposite direction. Therefore, and as a final point of criticism, the expected-utility framework cannot satisfactorily account for the whole of the recorded historical events - such that, in particular, it provides no satisfactory explanation for the liquidity crises occurred in the past.

A great part of the criticism made for the utility approach can be avoided by adopting the characterisation of the preference for liquidity proposed in this paper. Indeed, a simple mathematical expression is provided in Equations 8 and 9 to describe the money demand - i.e. the quantile function of the probability distribution describing the underlying risk. Moreover, as established in the first-order condition, the optimal amount of capital is corresponded to an optimal exchange between a flow of probability and the return offered by a certain flow of cash. Such representation reinterprets the Tobin's (1958) characterisation of liquidity-preference as behaviour towards risk. Additionally, the market money demand explicitly depends on the mean return and the volatility of the series of capital returns of the market portfolio in the new model, which are certainly observable variables.

The question remains, however, of whether the model can satisfactorily explains the evolution of the preference for liquidity in normal times as well as in times of turbulence. Before providing an answer to this question, I will ask the reader to wait until Section 6 . First, in the next section, the cost of capital will be determined on the basis of a balances equilibrium.

\section{The Cost of Capital as Determined by the Equilibrium in the Market of Cash Balances}

According to the model developed in Sections 2 and 3, the determinants of the money demand in a close financial market are of two kinds. Firstly, since the optimal levels of reserves explicitly depends on risk and risks are represented by probability functions belonging to the class of Gaussian probability distributions, the optimal surplus are ultimately determined by the mean return and the volatility of the series of capital returns of the market portfolio. Besides, by imposing the market balance to be equal to the sum of the balances demanded by investors, the mean return and the volatility of the market portfolio are expressed as the sum of the corresponding parameters representing the series of capital returns at the microscopic level (as stated in Equations 8 and 9). The other variable affecting the money demand is the cost of capital, defined as the return that allows investors to borrow or lend balances in the market.

We will additionally assume in the following that the total supply of cash holdings is controlled by some group of creditors, and the cost of capital will be determined in 
order to satisfy the necessary equilibrium condition that the flow of funds supplied to the market is equal to the aggregate balance demanded by intermediaries. Accordingly, letting $M$ denote the total amount of capital supplied by creditors and letting $L$ (as in Section 2) denote the total amount of funds invested on securities, the following equation must hold (see e.g. Friedman, 1970, and Howells and Bain, 2005):

$$
M=K_{\mu, \sigma}(r)=L \cdot k_{\mu, \sigma}(r)
$$

Replacing the liquidity-preference function $k_{\mu, \sigma}(r)$ according to Equation 9, we obtain that:

$$
m:=\frac{M}{L}=\sigma \cdot \Phi^{-1}(1-r)-\mu
$$

where the ratio $m=M / L$ represents a cash-to-risk ratio, which can be also interpreted as a supply-to-demand for transactions ratio or a relative credit supply. The equilibrium in the market of cash balances can be equivalently established in the following terms:

$$
R:=\frac{m+\mu}{\sigma}=\Phi^{-1}(1-r) \quad \Leftrightarrow \quad r=1-\Phi\left(\frac{m+\mu}{\sigma}\right)
$$

Within this context, both $M$ and $L$ are control variables - hence both lenders and borrowers can affect the monetary equilibrium. The expected return and the volatility of the market portfolio, on the other hand, can be regarded as variables of state, for they reflect the impact over the market of maintaining the current levels of supplied and demanded balances. Finally, the interest rate of equilibrium can be also considered as a state variable that is related to an optimal exchange of cash holdings and exposition to risk in the market.

The ratio $R$ thereby represents the rate at which firms agree to exchange the sure flow $(m+\mu)$ for a unit of volatility and can accordingly be regarded as the market price of risk. It can then be regarded as an alternative measure of risk to the Sharpe ratio, which, as it is well-known, is equal to the slope of a straight line relating the expected return to the volatility of every financial security transacted in the market, in such a way that $\mu=r+S \cdot \sigma$ (see Sharpe, 1964 and 1966). Unlike the Sharpe ratio, however, the measure $R$ is respectively induced to rise and to diminish in response to inflationary and deflationary trends, respectively characterised by increasing and decreasing $m$. Such a difference is a consequence of the fact that, while in the model of equilibrium of William Sharpe firms can borrow or lend any amount of capital at the interest rate $r$, in the alternative equilibrium condition established in Equation 11 the liquidity conditions are determined by the relative supply $m$. Accordingly, within any class of risks with the same market-price, different stocks of cash are necessarily corresponded to different riskparameters.

The rate $r=T_{X}(m)=1-\Phi(R)$ additionally represents the return obtained when investing one monetary unit on the underlying risk and can be accordingly regarded as the Internal Rate of Return on Risk (IRRR). Thus, while the Internal Rate of Return 
$(I R R)$ of a zero-coupon bond represents the opportunity cost of receiving a cash-flow at some future date instead of today (see, for example, Hull, 2000), the IRRR can be interpreted as the return to be paid for holding a given uncertain claim instead of investing on a non-risky zero-coupon bond with a predetermined maturity.

From the strictly mathematical viewpoint, the $I R R R$ corresponds to the probability that the current stock of reserves suffices to cover the expected imbalance of the market portfolio. In fact, the lower the $I R R R$, the lower the tail-probability that the excess of loss of the market portfolio was greater than the real money-supply. Such a situation is consistent with (overnight) markets where investors face less difficulties to adjust their end-of-day balances or equivalently, more liquid markets. By contrast, the tail-probability of the market portfolio increases with the $I R R R$ and so markets are more illiquid the greater the $I R R R$. Moreover, the higher the money spent in transactions with respect to the stock of capital in a given market, the higher its corresponding $I R R R$, since in this case the expansion of output is, to a greater extent, nominal in nature or, equivalently, more inflationary. Conversely, less inflated funds, characterised by greater cash-to-risk ratios, are assigned lower internal returns.

Figure 1: Interest Rate Elasticity of the Optimal Demand for Cash Balances.

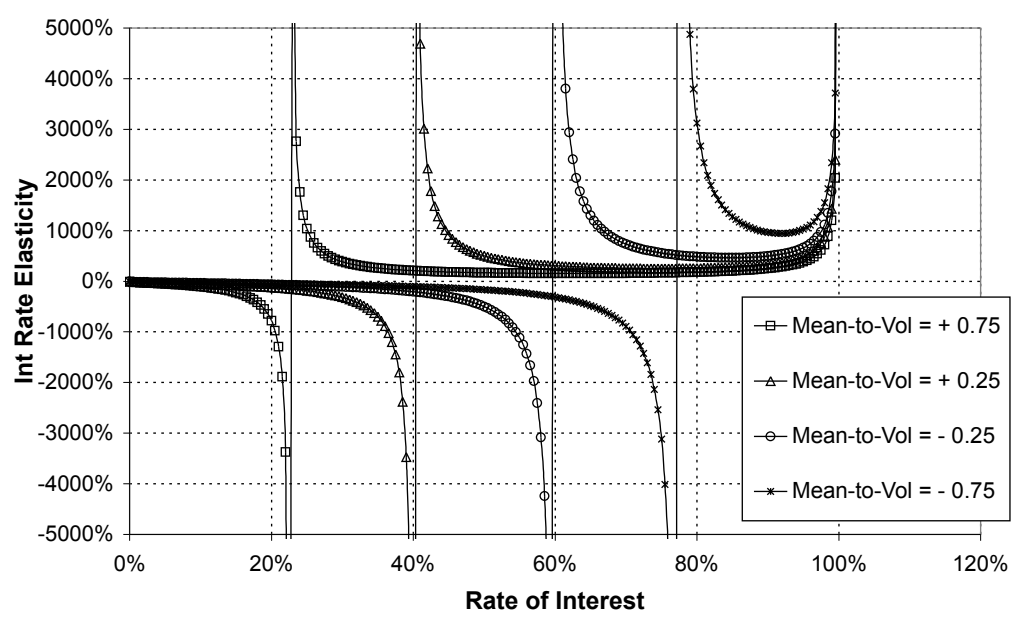

Finally, a word can be said about the instability of balances markets. In fact, as long as the market parameters are determined by Equation 10, changes in any of the control variables $M$ and $L$ must be followed by adjustments in $\mu, \sigma$ and the $I R R R$ in order to reestablish the balances equilibrium. In the particular case when the mean return and the volatility of the market portfolio remain unchanged, variations in the preference for liquidity can be explicitly established in terms of interest rate adjustments:

$$
\frac{\Delta k_{\mu, \sigma}(r)}{k_{\mu, \sigma}(r)}=\epsilon(r) \cdot \frac{\Delta r}{r} \quad \text { with } \quad \epsilon(r)=\frac{r}{k_{\mu, \sigma}(r)} \cdot \frac{d k_{\mu, \sigma}(r)}{d r}
$$

where the coefficient $\epsilon(r)$ represents the elasticity of the demand for cash balances with respect to the interest rate - equal to the percentage variation in demanded cash bal- 
ances in response to a percentage movement in the interest rate. From Equation 9, we obtain that the dependence on risk of the interest rate elasticity is in fact expressed as a dependence on the mean-to-volatility ratio $\mu / \sigma$ :

$$
\epsilon\left(r, \frac{\mu}{\sigma}\right)=-r \sqrt{2 \pi} \exp \left(\frac{\left[\Phi^{-1}(1-r)\right]^{2}}{2}\right) \cdot\left[\Phi^{-1}(1-r)-\frac{\mu}{\sigma}\right]^{-1}
$$

The sign of the elasticity thereby depends on the state parameters, in such a way that:

$$
\begin{aligned}
& \epsilon\left(r, \frac{\mu}{\sigma}\right)<0 \Leftrightarrow \Phi^{-1}(1-r)-\frac{\mu}{\sigma}>0 \Leftrightarrow r<1-\Phi\left(\frac{\mu}{\sigma}\right) \Leftrightarrow k_{\mu, \sigma}(r)>0 \\
& \epsilon\left(r, \frac{\mu}{\sigma}\right)>0 \Leftrightarrow \Phi^{-1}(1-r)-\frac{\mu}{\sigma}<0 \Leftrightarrow r>1-\Phi\left(\frac{\mu}{\sigma}\right) \Leftrightarrow k_{\mu, \sigma}(r)<0
\end{aligned}
$$

When $r=1-\Phi\left(\frac{\mu}{\sigma}\right)$, the magnitude of the elasticity is infinite, meaning that at this point the whole adjustment is produced in quantities.

In this context, the level $r=1-\Phi\left(\frac{\mu}{\sigma}\right)$ represents a turning-point in capital markets that separates two different environments: the first one satisfying $k_{\mu, \sigma}(r)>0$ and $\epsilon\left(r, \frac{\mu}{\sigma}\right)<0$, and the second one, characterised by $k_{\mu, \sigma}(r)<0$ and $\epsilon\left(r, \frac{\mu}{\sigma}\right)>0$. As depicted in Figure 1 , the interest rate elasticity is negative and non-increasing in $r$ when $r<1-\Phi\left(\frac{\mu}{\sigma}\right)$, but it is positive and $U$-shaped when $r>1-\Phi\left(\frac{\mu}{\sigma}\right)$. An asymptote is produced at the level $r=1-\Phi\left(\frac{\mu}{\sigma}\right)$, which is located to the left of the axis $r=0.5$ when $\mu>0$ and to the right of the axis $r=0.5$ when $\mu<0$. Hence, the market is the most unstable when the internal return on risk approaches to the level $r=1-\Phi\left(\frac{\mu}{\sigma}\right)$. Moreover, the greater the magnitude of the mean-to-volatility ratio, the more the asymptote respectively approaches to the axis $r=0$ and $r=1$ when $\mu>0$ and when $\mu<0$.

A complete characterisation of the dynamic of the market would require to describe the variation of the preference for liquidity in terms of the variations in all of the state variables. Besides, since every cash-to-risk ratio $m$ is corresponded to a set of parameters $(\mu, \sigma, I R R R)$, multiple equilibria are allowed and then additional conditions are required - determining an optimal path or a most probable state - in order to predict the future state of the market. The developing of such a model is beyond the scope of this paper. However, as long as the set of different combinations of the parameters which are compatible with the monetary equilibrium for a given relative stock $m$ are determined by Equation 10, it is still possible to describe the possible states of the market on the basis of a static approach. As will be proved soon in Section 5, a risk-structure of interest rates can be defined in this way, providing the optimal return of exchange between risk and money in a market characterised by a given pair of expected return and volatility.

\section{The Risk-Structure of Interest Rates}

Let us consider in the following some capital market that follows a certain regime with $m=$ constant. A risk-structure of interest rates on the plane of mean returns and 
volatilities is then determined by Equation 10, where each rate represents the return to be asked for receiving a sure cash-flow instead of some uncertain payment. Accordingly, as depicted in Figure 2, at any fixed level of volatility, the expected return and the internal rate of return on risk are inversely related. On the other hand, recall that the market price of risk is incremented when the $I R R R$ decreases and vice-versa (as established in Equation 11). Consequently, within a class of securities showing the same variability, risks offering different expected returns can be assigned the same IRRR (or the same market price) only if more equity is supplied to the portfolio containing the fund with the lower expected return. This result ultimately provides a theoretical explanation of why investors show liquidity-preference.

Figure 2: The Risk-Structure of Interest Rates as a Function of the Expected Return.
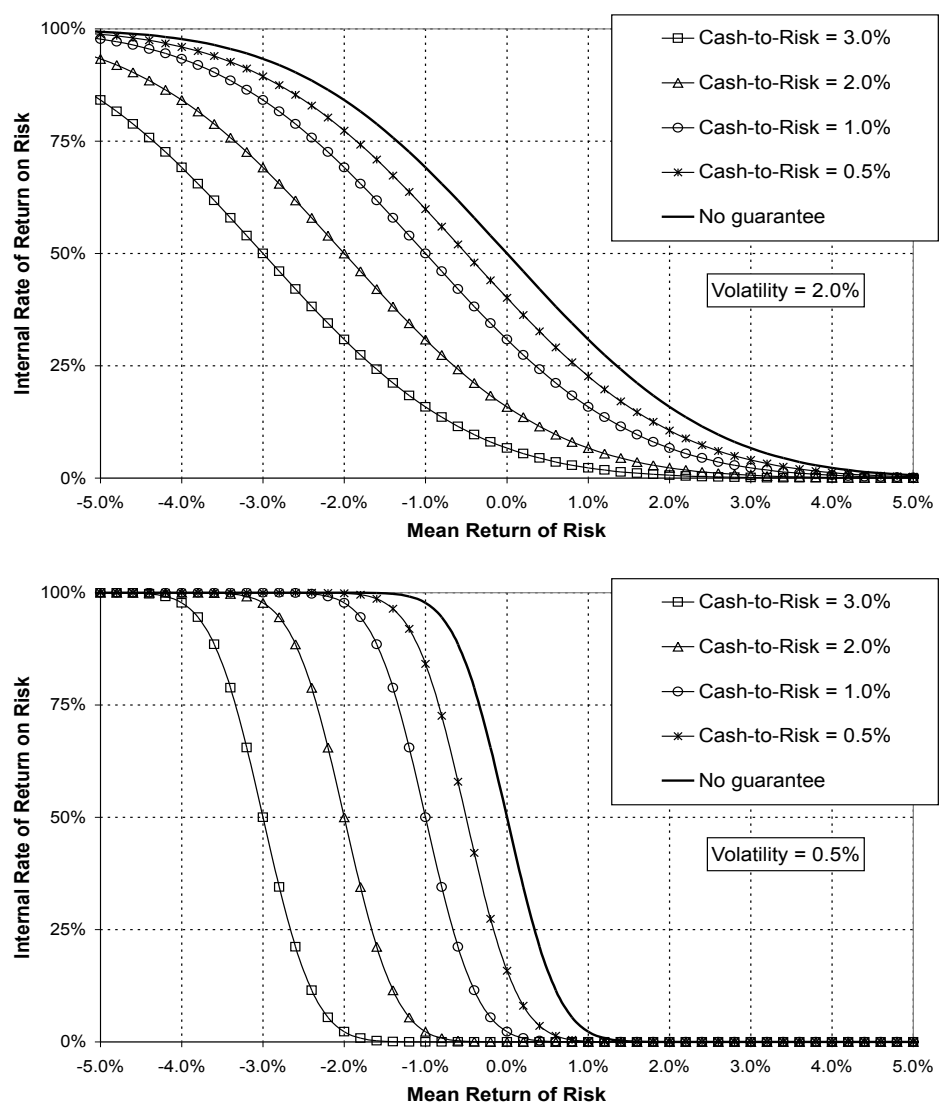

In Figure 3, the evolution of the internal return is shown as a function of the market volatility, given different fixed levels of the expected return. Thus, as depicted in the upper graph of Figure 3, within a class of securities offering the same positive expected return, the $I R R R$ always rises with variability, at the time that for every level of volatility, the $I R R R$ diminishes when the supply-to-demand ratio is increased. Consequently, the market price of risk can be inflated both by pumping liquidity and by reducing the variability of the market portfolio - relations that are compatible with economic intuition. In the lower graph of Figure 3, the risk-structure is shown for a class of funds 
offering negative expected returns. Note that the relationship between internal returns and volatilities is inverted when the surplus is lower than the expected loss, in such a way that in this range higher internal returns (or lower market prices) are obtained for lower volatilities.

Figure 3: The Risk-Structure of Interest Rates as a Function of Volatility.
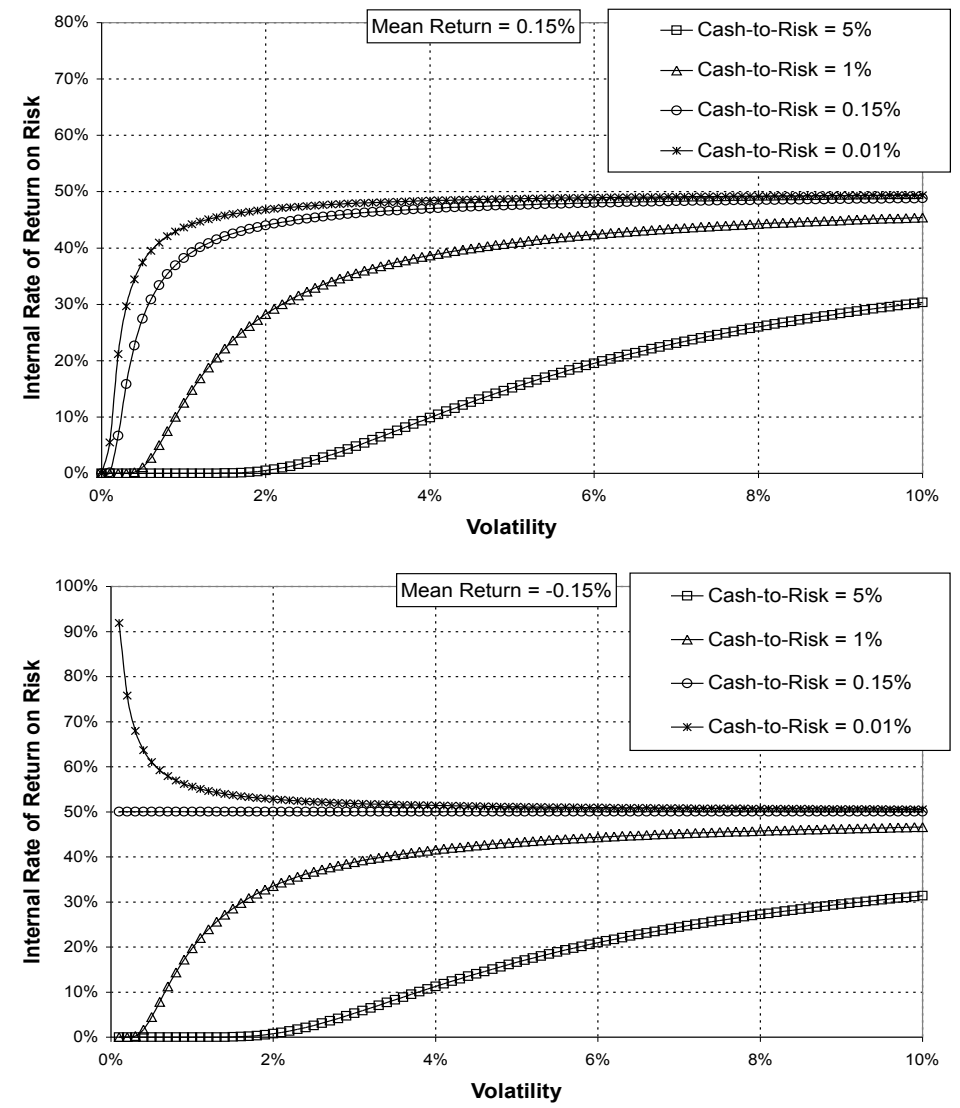

Notice that the following relationships are additionally obtained from Equation 11:

$$
\begin{aligned}
& I R R R>0.5 \Leftrightarrow \frac{m+\mu}{\sigma}<\Phi^{-1}(0.5)=0 \Leftrightarrow \mu<-m \\
& I R R R<0.5 \Leftrightarrow \frac{m+\mu}{\sigma}>\Phi^{-1}(0.5)=0 \Leftrightarrow \mu>-m
\end{aligned}
$$

Hence the case $I R R R>0.5$ is corresponded to the situation when the average capital loss endured by the market portfolio is higher in magnitude to the relative stock $m$, while the case $I R R R>0.5$ is related to the situation when the magnitude of the average capital loss is lower than the relative stock $m$. Accordingly, the cases $I R R R>0.5$ and $I R R R<0.5$ respectively characterises insolvent and solvent market portfolios. The asymptote separating both trends at the axis $r=0.5$ corresponds to the case when the demanded and supplied levels of reserves are equal in magnitude. Besides, $\sigma \rightarrow+\infty$ when $I R R R \rightarrow 0.5$, no matter whether this level is approached from the left or the 
right of the axis $r=0.5$. Indeed, maximum uncertainty can be expected around the level $I R R R=0.5$, for at this point the market portfolio is not solvent, as in the case $I R R R>0.5$, nor insolvent, as in the case $I R R R<0.5$, so that its credit quality is not determined.

Some general rules concerning the evolution of the market can thus be given by using a partial equilibrium approach. Indeed, notice on the one hand, as shown in Figure 2, that the equilibrium expected return tends to the cash-to-risk ratio (so that the market price of risk tends to zero) when the IRRR tends to 0.5 (see Equation 11). On the other hand, as depicted in Figure 3, the internal return on risk tends to the value $r=0.5$ when the volatility tends to infinite. Besides, the more the $I R R R$ approaches to 0.5 , the greater the volatility adjustment that is required to account for a same absolute variation in the $I R R R$. Consequently, the model predicts the appearance of volatility jumps in response to movements in the $I R R R$ if this variable is close enough to the level $r=0.5$. Moreover, since the concavity of the curve relating the $I R R R$ to $\sigma$ increases as the risk-to-cash ratio is diminished and the curve eventually degenerates when $m=0$, more drastic volatility movements are expected for lower ratios.

In conclusion, the mean return and the volatility of the market portfolio, as well as the internal return on risk, can be regarded as physical properties of markets, which at equilibrium are connected to each other according to Equation 10 for any given level of the relative stock of money $m=M / L$. Consequently, the equilibrium depends on the interactions between borrowers and lenders on the one hand, who respectively control the demand and the supply of capital, and the response of the market on the other, which can be regarded as the involuntary output of the decisions simultaneously and independently made by investors, intermediaries and monetary authorities, and which is corresponded to the probability distributions describing the processes of percentage returns. The fact that $\mu$ and $\sigma$ are observable variables that can be measured on the base of historical data, implies that the model can be empirically tested. This task will be performed in the coming sections.

\section{Empirical Evidence}

The theoretical approach presented in the previous sections can be applied to characterise the cost of capital in different economic contexts. Thus, for example, at the corporate level, it can be used for the design of a capital allocation mechanism in financial conglomerates (as proposed by Dhaene et al., 2003, Goovaerts et al., 2005, and Mierzejewski, 2006 and 2008). In this case, the Gaussian random variables $X_{i}$ represent the capital $P \& L$ of the portfolios maintained by the business units and the $I R R R$ represents the internal cost of capital, i.e. the return to be imposed on the transactions of cash balances inside the institution. Alternatively, at the macroeconomic level, the model can be applied to deduce a (theoretically justified) expression for the money demand of the economy. In this situation, the aggregate exposure $X$ should be related to the series of capital $P \& L$ of the level of nominal income.

But the model can be also used to describe the equilibrium in some closed market of 
balances, where a total stock of cash $M$ is supplied by creditors and stockholders. Financial intermediaries, on the other hand, spend the (nominal) quantities $L_{i}$ on securities and demand equity up to the optimal levels $k_{i}(r)$ defined in Equation 8, in such a way that the total demand for capital in the market is equal to $L \cdot k_{\mu, \sigma}$, where $k_{\mu, \sigma}$ denote the market liquidity-preference (defined in Equation 9), $\mu$ and $\sigma$ denote the risk-parameters of the market portfolio and $L$ represents the total volume spent on the transactions of securities.

Figure 4: Twenty Years of Evolution of the DowJones and the Nasdaq Composite Indexes and their Corresponding Daily Transacted Funds.
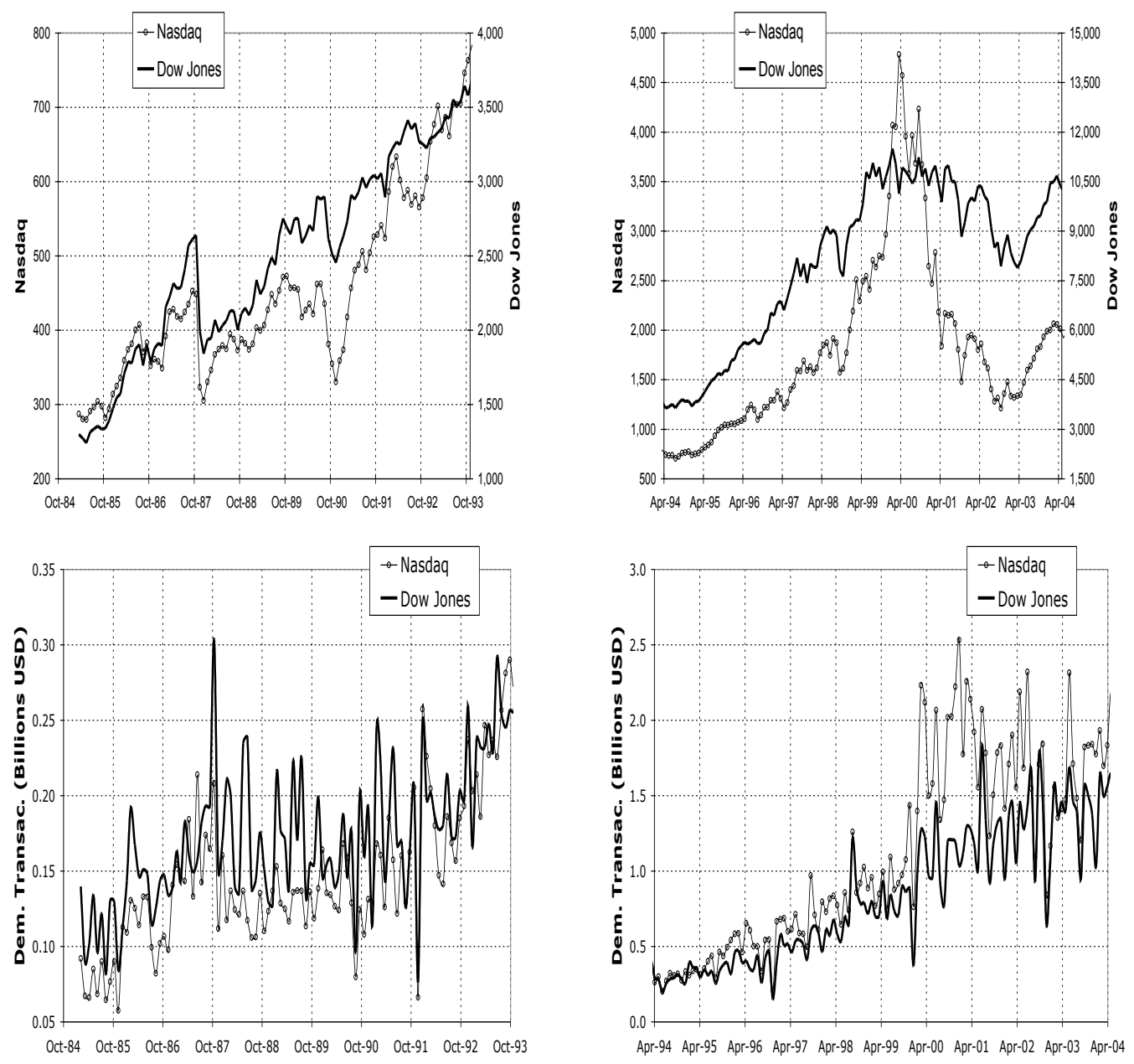

Assuming, in addition, that all the relevant information for investment decisions is contained in the values assigned in the stock exchange, the series of capital returns of the level of prices in this market should determine the riskiness of the market portfolio. This will be the framework adopted in the following for the empirical verification of the model. The variables under analysis will be the DowJones and the Nasdaq composite indexes, which respectively represent the industrial and the Information $\&$ Technology (IT) sectors of the economy of United States. The daily valuations of these indexes are depicted in Figure 
4, together with the amounts of funds daily spent on transactions in the corresponding sectors. The data have been obtained from http://www.yahoo.com/finance.

Two episodes of crisis are clearly distinguished in Figure 4, occurring in October 1987 and April 2000, and respectively known as the Black Monday and the dot-com bubble. In fact, on Monday October 19th, 1987, the DowJones lost more than $25 \%$ of its value to recover only about $5 \%$ the day after, thus accumulating in one week, in the two consecutive days, losses over $40 \%$ and $35 \%$ respectively. The Nasdaq, in the meantime, lost more than $10 \%$ of its value the same day and nearly $10 \%$ the day after, thus accounting for weekly losses around $20 \%$ and $30 \%$ on October 19th and 20th respectively. These are among the most severe declines observed during the whole past century. A striking feature of the episode is the short time that took the bubble to explode and its lack of fundamentals, for no major news or events appeared during the prior days to the crash.

Unlike the stock crash of October 1987, the episode of April 2000 mainly affected the IT companies. In fact, while the DowJones attains a maximum at 11,722.98 points on January 14th, 2000, and then falls until reaching 9,811.24 points on March 14th, 2000, the Nasdaq attains a maximum at 5,048.62 points on March 10th, 2000, and then falls until reaching 3,400.91 points on May 31st, 2000, in this way respectively accounting for losses of $35 \%$ and 15\% approximately. It can be also noted in Figure 4 that the funds demanded for transactions followed a growing path during the nineteen nineties, a fact that is consistent with the liberalisation of capital markets and the expansionary monetary policy followed by the Federal Reserve Bank in that period (see Figure 6). Moreover, although the total inflows of capital are shared in roughly equal parts most of the time, such a tendency is abandoned in the period starting shortly after April 1999 and extending until shortly before April 2003. It is well-known, indeed, that towards the mid-nineties, a sentiment of growing confidence about the future of the dot-com firms predominated. As a consequence, the credit conditions were facilitated to this industry, both through the reduction of premiums and controls, as through the publishing of new stock.

Let us then investigate whether the trends followed by the mean returns and the volatilities of the series of capital returns of the DowJones and the Nasdaq, respectively depicted in the upper and the lower rows of Figure 5, are consistent with the balances equilibrium described by Equations 10 and 11. The mean returns have been estimated as the average of the daily percentage variations of the indexes observed in the past ninety working days, while the volatilities have been calculated as the mean standard error:

$$
\mu_{t}=\frac{1}{90} \cdot \sum_{i=t-89}^{t} X_{i} \text { and } \sigma_{t}=\sqrt{\frac{1}{90} \cdot \sum_{i=t-89}^{t}\left(X_{i}-\mu_{t}\right)^{2}}
$$

Thus, in the first place, every peak in the volumes of funds spent on assets shown in the second row of Figure 4 should be corresponded to a pair of mean and volatility adjustments in Figure 5. By comparing both figures, we can verify that this is indeed the case. In particular, the peaks of trading activity occurred in October 1987 and April 2000 are accompanied by the major changes in the risk parameters. As a matter of fact, the volatilities of the series of percentage returns of the DowJones and the Nasdaq respectively 
multiplied by more than three and more than four times in October 1987, while their mean returns suddenly felt from levels around $+0.1 \%$ to levels around $-0.3 \%$. Regarding the episode of April 2000, there is no evidence of turbulence in the DowJones, for only small variations in the risk-parameters are observed - as it is expected indeed, since this index did not burst on that date. The volatility of the Nasdaq, in the meantime, was amplified 1.5 times approximately, although the major adjustment affected its expected return, which between February 2000 and May 2000 felt from a historical maximum over $0.6 \%$ to a level around $-0.1 \%$.

Figure 5: Expected Returns and Volatilities of the Series of Capital $P \& L$ of the DowJones and the Nasdaq Composite Indexes.
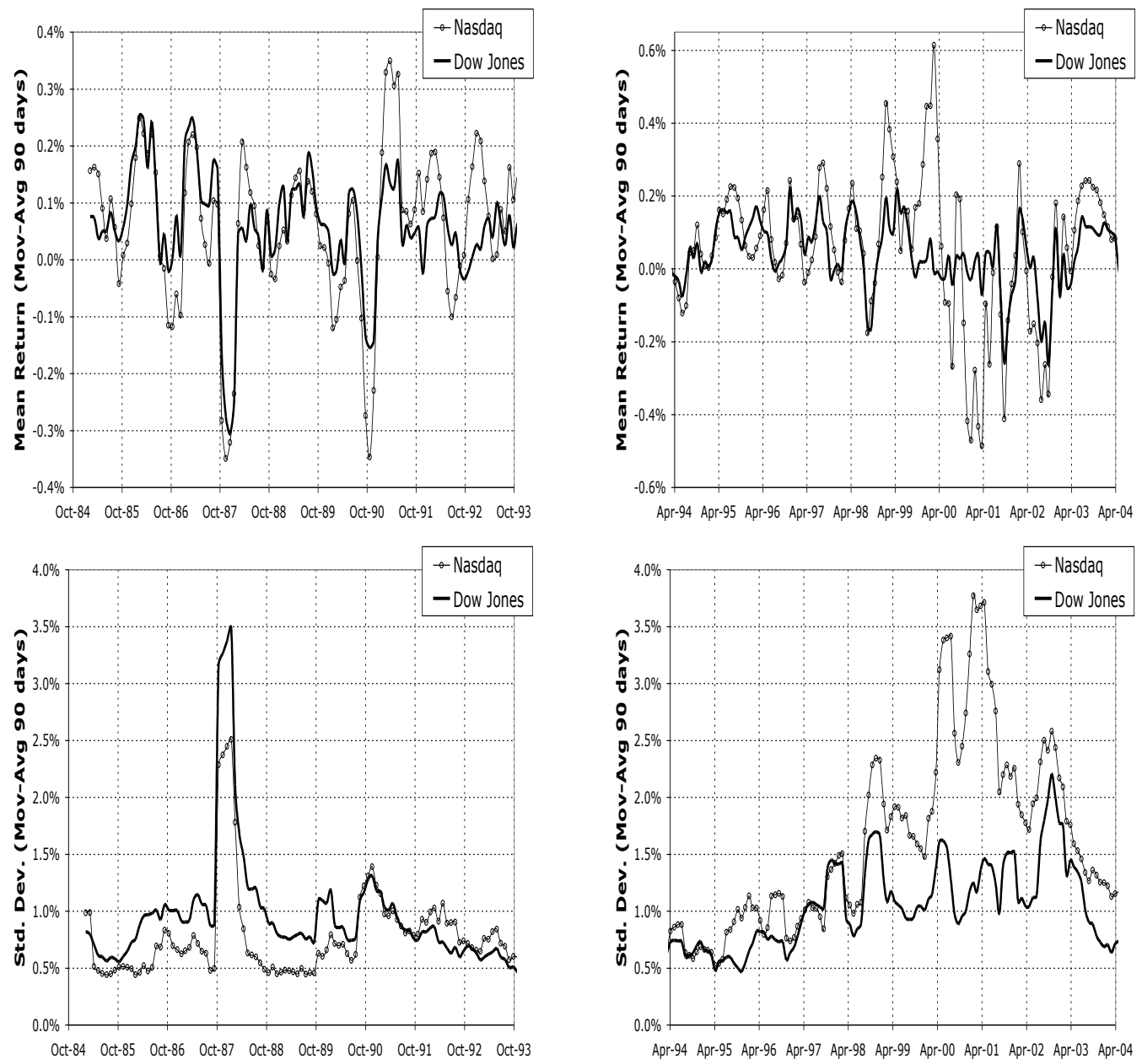

Other facts predicted by the model can be empirically verified. In fact, from Equation 11 , we obtain that if the $I R R R$ is rising (i.e. if the market price of risk is diminishing) while the relative supply $m=M / L$ is constant, either the expected return must be reduced or the volatility must augment. By contrast, if the $I R R R$ is diminishing (i.e. if the market price of risk is rising) while the relative supply $m=M / L$ is constant, either the expected return must augment or the volatility must be reduced. On these 
grounds, we can say that under any of the combined regimes $(\mu \downarrow, \sigma \uparrow)$ and $(\mu \uparrow, \sigma \downarrow)$, the risk-parameters push the market in the same direction: i.e. the $I R R R$ is incremented and the market price of risk is reduced in the former case, while the $I R R R$ is reduced and the market price of risk is incremented in the later. In any different situation, i.e. either when $(\mu \downarrow, \sigma \downarrow)$ and when $(\mu \uparrow, \sigma \uparrow)$, the effects of the mean return and the volatility compensate each other. We then conclude that the most severe liquidity adjustments should be characterised by sudden movements of opposite sign affecting the risk-parameters. Several episodes occurred between October 1984 and April 2004 follow this pattern, like those observed in October 1990, April 1998 and April 2002, as well as in the stock crashes of October 1987 and April 2000 (see Figures 4 and 5).

Figure 6: Federal Funds Rate.
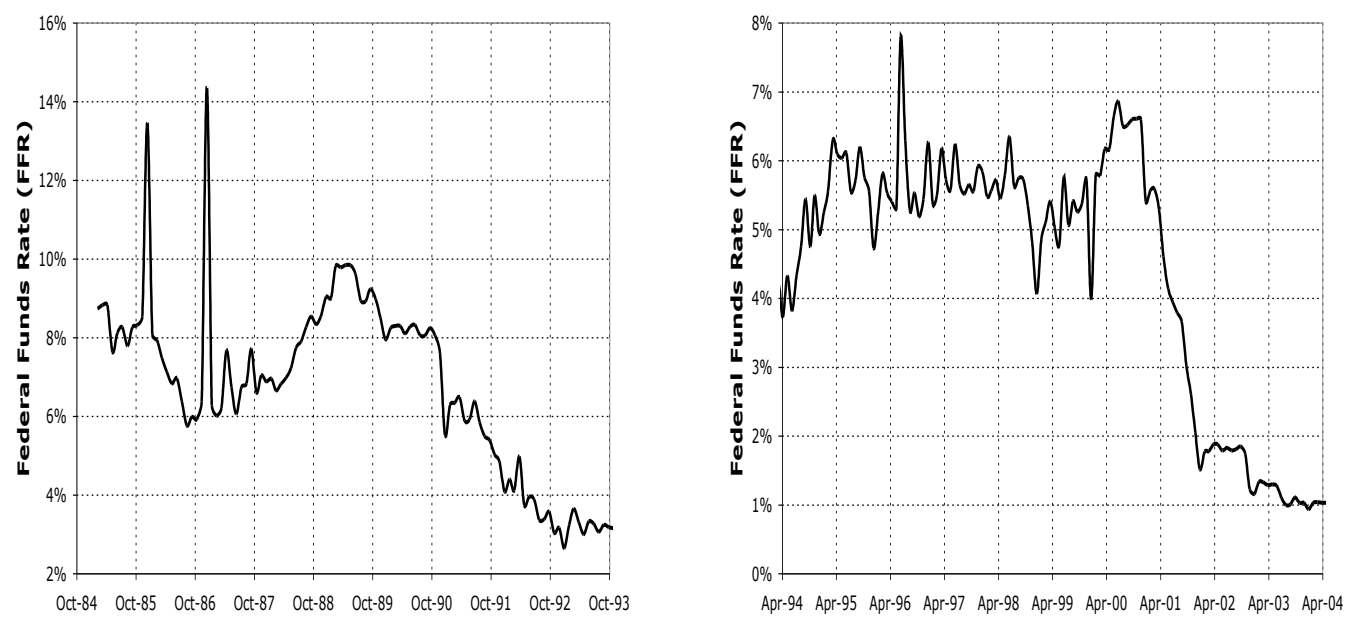

To complete the description of the monetary equilibrium, still the paths followed by the liquidity-preference function and the internal rate of return on risk have to be analysed. This will be done in the next sections by separately considering two different settings. Thus, first the level of the rate of interest will be regarded as given in Section 7 (as in a competitive framework), so that the adjustments in markets will be exclusively produced in quantities, i.e. they will exclusively affect the variables $M$ and $L$. Next in Section 8, the cash-to-risk ratio $m=M / L$ will be fixed, in such a way that the equilibrium will be reestablished by exclusively affecting the $I R R R$.

\section{Maintaining Equilibrium with Quantity Adjustments}

We will suppose in the following that firms can exchange their overnight balances at the Federal Funds Rate, whose evolution is depicted in Figure 6. In other words, we will assume that depositary institutions (the only financial institutions that are legally allowed to directly execute transactions with the Federal Reserve Bank, see e.g. Edwards and Sinzdak, 1997, and Howells and Bain, 2005) do not charge any risk premium nor transaction costs when lending money to financial intermediaries, and so do the later when offering credit to firms and private investors. Although this is certainly an unrealistic 
hypothesis, it will provide us with an upper bound for the preference for liquidity of the market, for raising the cost of capital induces individuals to reduce their levels of reserves. Besides, since in general raising the level of the interest rate increases the elasticity of the liquidity-preference function (as depicted in Figure 1), we will also obtain a lower bound for this coefficient.

Figure 7: Preference for Liquidity and Demanded Reserves.
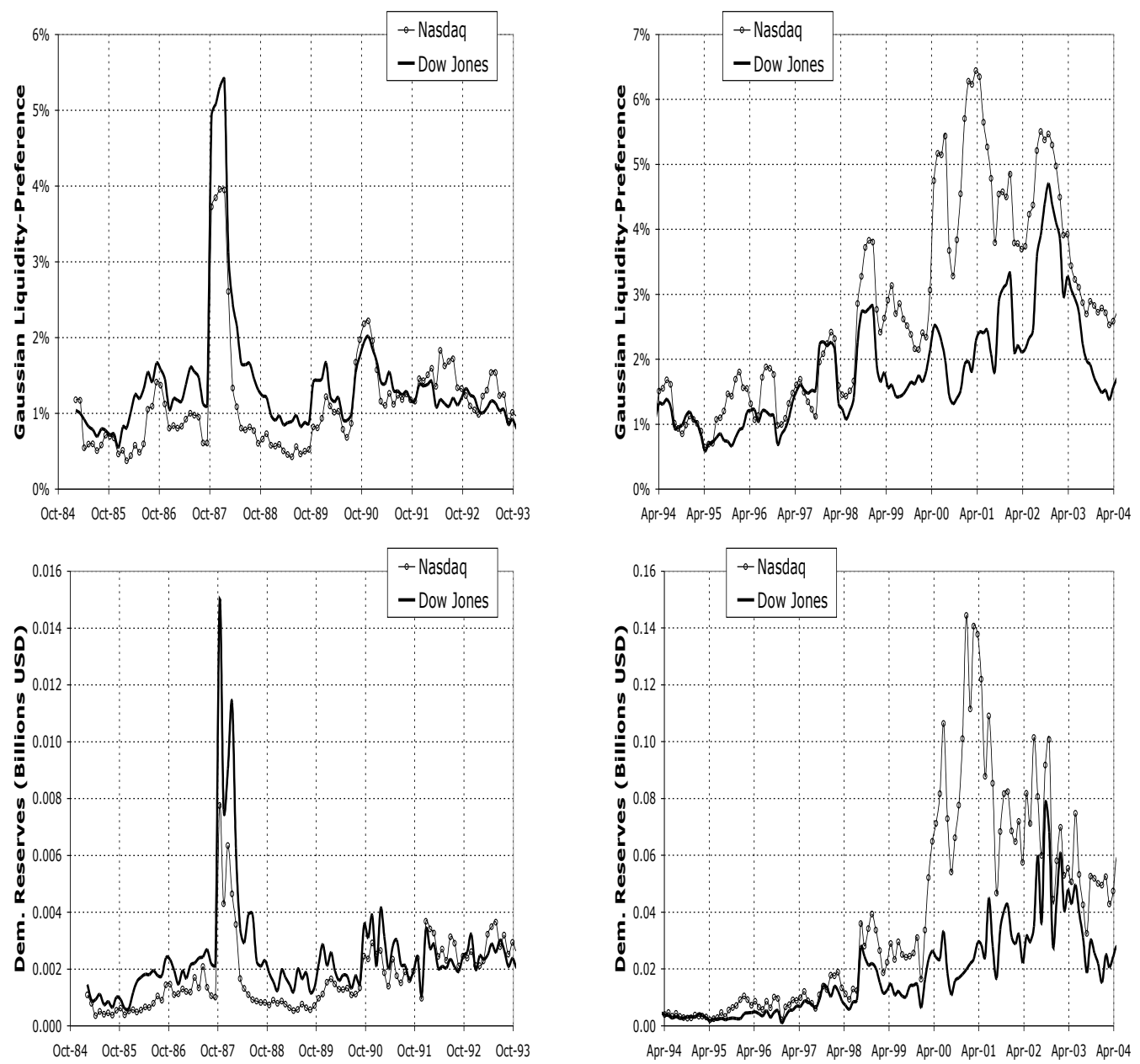

Let $r_{0}$ denote the Federal Funds Rate, then the optimal amount of reserves demanded at the aggregate level is given by:

$$
K_{\mu, \sigma}\left(r_{0}\right)=L \cdot k_{\mu, \sigma}\left(r_{0}\right)=L \cdot\left[\sigma \cdot \Phi^{-1}\left(1-r_{0}\right)-\mu\right]
$$

The question of whether the crises episodes already described are corresponded to adjustments in the liquidity-preference and the demanded reserves functions is answered by inspecting the graphs depicted in Figure 7.

Indeed, as depicted in the first column of Figure 7, both the preference for liquidity and the demand for cash balances are sharply incremented around October 1987. In the case 
of the DowJones, the level of demanded reserves is multiplied by eight around October 1987 (going from about USD $2 \mathrm{MM}$ to about USD $16 \mathrm{MM}$ ), a result that is compatible with the fact that the liquidity demand was multiplied by five around October 87 (rising from $1 \%$ to $5 \%$ ), while the level of demanded cash-balances $L$ was multiplied by 1.5 (rising from less than USD $200 \mathrm{MM}$ to about USD $300 \mathrm{MM}$ ). Regarding the Nasdaq, the level of demanded reserves and the preference for liquidity were respectively amplified about 8 and 6 times, while the demand for cash balances was multiplied by 1.3 approximately. Notice also that the effects of the crisis were endured in both industries, although the magnitude of the required adjustment was greater for the DowJones composite index. Finally, also the short-lasting nature of the event is captured by the liquidity-preference function, since around October 1988 this coefficient had already attained the levels that had predominated before the crisis erupted.

Regarding the episode of April 2000, as shown in the second column of Figure 7, although the liquidity-preference of both indexes rose steadily from roughly the first quarter of 1997 until the last quarter of 2002, most of the time the magnitude of this coefficient is greater for the Nasdaq, specially after April 2000. The crisis signaled at this point must then be regarded as one particular adjustment occurred at the middle of a more extended period of turbulence primarily affecting the IT industry. Inspecting the graph located to the lower right corner of Figure 7, we can additionally notice that the increment in the preference for liquidity is partly compensated by a reduction in the funds demanded for transactions $L$ (see also Figure 4), in such a way that only from the beginnings of the year 2000 until the end of 2003 the balances demanded for precautionary motives surpassed the levels considered as normal up to that moment. However, since the lift of the liquidity-preference of the Nasdaq is sharpest on April 2000, the burst of the bubble can be established at this point, in accordance to the analysis of the previous section.

In conclusion, the two episodes of crisis so far analised can be fully described by means of the money demand functions defined in Equations 9 and 13, in the sense that not only the moments when the bubbles bursted are precisely determined, also the main characteristics of the crises are satisfactorily explained.

\section{Maintaining Equilibrium with Adjustments in the Cost of Capital}

Let us now assume that firms peg their cash-to-risk ratios to a fixed proportion $\alpha$, i.e. $m=K / L=\alpha$. Such could be a restriction established by a regulatory authority, but it could be also imposed as a tacit requirement in markets with informational asymmetries. As a matter of fact, when intermediaries cannot fully observe the portfolios held by their customers, the leverage ratios provide a signal of the capacity to pay liabilities back and thus explicitly affect the price of debt. The equilibrium internal return on risk under such circumstances is obtained by replacing $m=\alpha$ in Equation 11: 


$$
r_{\alpha}=1-\Phi\left(\frac{\mu+\alpha}{\sigma}\right)
$$

Hence $r_{\alpha} \rightarrow 0.5$ when $\sigma \rightarrow \infty$ (see Figure 3 ). In fact, as already stated in Section 5 , under regimes that maintain a constant relative stock of money, decreasing expected return and increasing volatility are both markets trends that push the induced internal return $r_{\alpha}$ to the axis $r=0.5$ (or push the market price of risk to zero) and consequently push the market to more unstable states.

Figure 8: Internal Rate of Return on Risk (IRRR) and Interest Rate Elasticity of the Liquidity Demand with Constant Relative Supply.
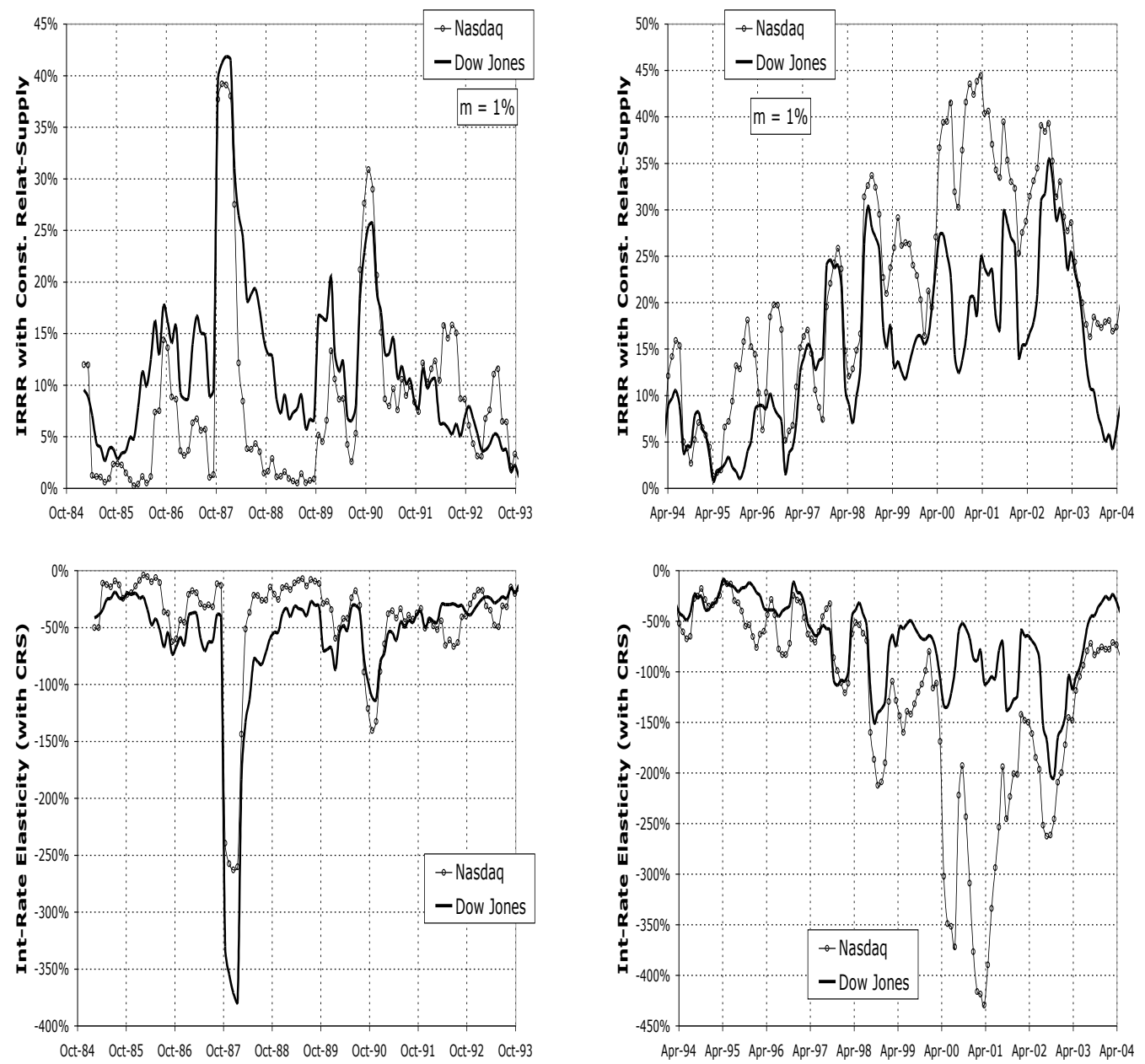

From Equations 12 and 14, the following expression is obtained for the elasticity:

$$
\epsilon_{\alpha}=-r_{\alpha} \frac{\sigma \sqrt{2 \pi}}{\alpha} \cdot \exp \left[\frac{(\mu+\alpha)^{2}}{2 \sigma^{2}}\right]
$$

Therefore, the sign of the interest rate elasticity is always negative, which means that 
increments of the cost of capital are always followed by reductions in the amount of demanded cash balances and vice versa. Besides, the magnitude of the elasticity converges to infinite when $\sigma \rightarrow \infty$, i.e. $\left|\epsilon_{\alpha}\right| \rightarrow \infty$ when $\sigma \rightarrow \infty$. This result reinforces the claim stated in the previous paragraph, that the market becomes more unstable as $\sigma \rightarrow \infty$ and $r_{\alpha} \rightarrow 0.5$.

The internal returns on risk and the elasticities of the demand for cash balances, computed according to Equations 14 and 15, are respectively depicted in the first and the second rows of Figure 8, when the cash-to-risk ratio is pegged to the level $\alpha=1 \%$. Notice that jumps in $r_{\alpha}$ and $\epsilon_{r}\left(r_{\alpha}\right)$ are produced around the episodes of crisis - in the same way that this events were distinguished by jumps in the preference for liquidity when the cost of capital was peg to the Federal Funds Rate in the previous section. In fact, around October 1987, $r_{\alpha}$ drastically rose to a historical maximum, while $\epsilon_{r}\left(r_{\alpha}\right)$ suddenly felt to a historical minimum. Besides, the signal appeared in both indexes and its influence was short-lasting, in accordance to the empirical facts characterising this crisis. Regarding the episode of April 2000, the times of turbulence are located on a broader interval, with a clear predominance of the signals related to the Nasdaq, in consistence with the fact that only this index crashed on that date, and the most unexpected movements are produced precisely in April 2000.

We can then conclude that many of the facts observed in stock markets can be satisfactorily explained within the theoretical framework proposed in this paper. Notice, however, that although in this context $k_{\mu, \sigma}$ and the IRRR can be regarded as signals of liquidity adjustments, such signals only appear after the corresponding events have been produced and hence they cannot be used to make predictions. This is a consequence of the fact that only a partial equilibrium approach has been followed in this paper and hence the equilibrium ultimately depends on variables whose evolution is unknown (as it is the case with $L, \mu$ and $\sigma$ ) and have to be treated in practice as exogenous variables. Although this is certainly an important limitation, the model still provides a precise definition of liquidity and of instability, capable of accounting for the behaviour of capital markets both under normal circumstances and in times of turbulence - as illustrated with the empirical analysis so far developed.

\section{Conclusions}

As long as in perfect capital markets funds can be lend and borrow without restrictions at a single and exogenously determined interest rate, financial institutions can always adjust their surpluses and accordingly, their market values do not depend on their capital structures (Modigliani and Miller, 1958). However, this mechanism does not work efficiently in markets where opaque intermediaries establish contractual liabilities with credit sensitive customers (Merton, 1974, 1977 and 1997). Within this framework, the role of financial institutions is that of providing the services of hedging and diversification to customers that cannot trade by themselves. Optimal option-based arrangements, contingent on the outstanding surplus (equal to difference between the outstanding assets and liabilities) at the maturity date, can then be issued to assure that the value of the firm is maximised and the cost of insolvency is minimised. 
An alternative approach is proposed in this paper for the characterisation of markets where intermediaries can only hedge and diversify up to a limited extent and are accordingly obliged to rely on deposit insurance and capital cushions. The optimal contracts are established in actuarial terms, in such a way that the expected insured capital gain of the intermediary's portfolio is maximised and the cost of bankruptcy is minimised (see Equations 5 and 7), while the optimal liquidity demands are expressed as the quantile function of the probability distributions describing risks (as in Equations 6 and 8).

The level of reserves demanded by the market is thereby characterised by the sum of the surpluses demanded by investors, intermediaries and customers. As a result, the market expected returns and volatilities are expressed as the weighted averages of the mean returns and volatilities of the individual portfolios (see Equation 9). The role of investors when deciding their balances in deregulated markets can then be related to that of subsidiaries in decentralised organisations, where an internal cost of capital is given and the total surplus is equal to the sum of the divisional contributions (see Merton and Perold, 1993, and also Mierzejewski, 2006 and 2008).

More generally, when the supply of reserves is controlled by creditors, the cost of capital is endogenously determined in order to satisfy the equilibrium in the market of cash balances (as in Equations 10 and 11). In this context, the market interest rate represents the return obtained when investing one monetary unit on risk and can be accordingly regarded as the Internal Rate of Return on Risk $(I R R R)$. Given any fixed pair of liquidity supply and balances demanded for transactions, a risk-structure of interest rates is determined in the plane of expected returns and volatilities (see Figures 2 and 3).

In conclusion, variations in the rate of growth of the funds spent on transactions or in the stock of money must be necessarily followed by market adjustments reflected in the relative prices of securities. Up to some extent, such movements will be compensated by the internal return on risk, but also the mean return and the volatility of the market portfolio are expected to be affected, for these parameters completely characterise risks in a Gaussian setting. Different scenarios are thus corresponded to different combinations of the involved parameters, some of which can be related to more stable and others to more vulnerable states. In this way, both normal times, when credit is plentiful, as well as times of financial turmoil, are possible in the model, depending on the flows of capital and the paths followed by the risk parameters. The equilibrium mechanism of capital markets is thus essentially physical in nature - and not only affected by psychological and informational shocks. The predictions of the model can be verified by analysing the historical data.

\section{References}

[1] Choi, W.G., and Oh, S., 2003. A Money Demand Function with Output Uncertainty, Monetary Uncertainty, and Financial Innovations. Journal of Money, Credit and Banking 35 (5), pp. 685-709.

[2] Dhaene, J., Goovaerts, M. and Kaas, R., 2003. Economic Capital Allocation Derived from Risk Measures. North American Actuarial Journal 7 (2), pp.44-59. 
[3] Edwards, Ch.L. and Sinzdak, G. 1997. Open Market Operations in the 1990s. Federal Reserve Bank Bulletin, November 1997, pp. 859-874.

[4] Friedman, M., 1970. A Theoretical Framework for Monetary Analysis. The Journal of Political Economy 78 (2), pp. 193-238.

[5] Goovaerts M.J., Van den Borre E. and Laeven R., 2005. Managing economic and virtual economic capital within financial conglomerates. North American Actuarial Journal 9 (3), pp.77-89.

[6] Holmstrom, B., and Tirole, J., 2000. Liquidity and Risk Management. Journal of Money, Credit and Banking 32 (3), pp.295-319.

[7] Howells, P. and Bain, K., 2005. The Economics of Money, Banking and Finance. Prentice Hall.

[8] Hull, J.C., 2000. Options, Futures and Other Derivatives. Fourth Edition. Prentice Hall.

[9] Jensen, M.C., 1986. Agency Costs of Free Cash Flow, Corporate Finance, and Takeovers. The American Economic Review 76 (2), pp. 323-329.

[10] Merton, R.C., 1974. On the Pricing of Corporate Debt: The Risk-Structure of Interest Rates. Journal of Finance 29 (2), pp. 449-470.

[11] Merton, R.C., 1977. An Analytic Derivation of the Cost of Deposit Insurance and Loan Guarantees. Journal of Banking and Finance 1, pp.3-11.

[12] Merton, R.C., 1997. A Model of Contract Guarantees for Credit-Sensitive, Opaque Financial Intermediaries. European Finance Review 1 (1), pp.1-13.

[13] Merton, R.C. and Perold, A.F. (1993). Theory of Risk Capital in Financial Firms. Journal of Applied Corporate Finance 5, pp. 16-32.

[14] Mierzejewski, F., 2006. Optimal Capital Allocation Confronting Bankruptcy and Agency Costs. Bank- en Financiewezen 2006/2, pp. 72-77.

[15] Mierzejewski, F., 2008. The Economic Capital of Opaque Financial Institutions. Journal of Applied Economic Sciences 3 (Issue 3, Number 5), pp 232-245.

[16] Modigliani, F. and Miller, M.H., 1958. The Cost of Capital, Corporation Finance and the Theory of Investment. The American Economic Review 48 (3), pp. 261-297.

[17] Sharpe, W.F., 1964. Capital Asset Prices: A Theory of Market Equilibrium under Conditions of Risk. The Journal of Finance 19 (3), pp. 425-442.

[18] Sharpe, W.F., 1966. Mutual Fund Performance. The Journal of Business 39 (1), pp. 119-138.

[19] Tobin, J., 1958. Liquidity Preference as Behavior Towards Risk. The Review of Economic Studies 25 (2), pp. 65-86. 